\title{
Development of a Microwave Discharge Ion Thruster using Argon
}

\author{
By Naoji YAMAMOTO ${ }^{1)}$, Makoto MIYOSHI ${ }^{1)}$, Yoshiyuki TAKAO ${ }^{2)}$ and Hideki NAKASHIMA ${ }^{1)}$ \\ 1) Department of Advanced Energy Engineering Science, Kyushu University, Fukuoka, Japan;, \\ 2) Oita National College of Technology, Oita, Japan \\ (Received May 2nd, 2008)
}

\begin{abstract}
Thrust performances in a microwave discharge ion thruster using argon as the propellant were investigated for possibility of alternative propellant of xenon. First, the ion beam currents using a $10 \mathrm{~cm}$ class were measured. The ion beam currents with argon propellant are larger than those with xenon propellant at $P_{\mathrm{i}}>24 \mathrm{~W}$ in the same configuration. The propellant utilization and ion beam production cost are 0.50 and $440 \mathrm{~W} / \mathrm{A}$, respectively at $2.45 \mathrm{GHz}$ microwave input power of $37 \mathrm{~W}$ and argon gas flow rate of $2.28 \mathrm{sccm}$. Next the ion beam currents of $2 \mathrm{~cm}$ class ion thruster were measured. The optimum mass flow rate is $0.4 \mathrm{sccm}$, which is larger than that using xenon. This would be due to the smaller ionization cross section and lighter mass than those of xenon. The propellant utilization efficiency and ion beam production cost are $0.73,750 \mathrm{~W} / \mathrm{A}$, respectively at argon mass flow rate of $0.4 \mathrm{sccm}$ and input power of $16 \mathrm{~W}$. This performance of ion thrusters using argon competes against that using xenon.
\end{abstract}

Key Words: Ion Thruster, Electron Cyclotron Resonance, Microwave Discharge, Thrust Performance, Argon

\section{Nomenclature}

e :electronic charge

$g \quad$ :acceleration of gravity

F : : thrust

$I_{b} \quad$ :extracted ion beam current

$I_{s p} \quad$ :specific impulse

$m_{i} \quad$ :ion mass

$\dot{m}_{i} \quad$ :mass flow rate for ion source

$P_{i} \quad$ :incident microwave power

$P_{r} \quad$ :reflected microwave power

$V_{b} \quad$ :beam voltage

$\alpha \quad$ :ratio of doubly charged ion current to singly charged ion current

$\varepsilon_{c} \quad$ :ion beam production cost

$\gamma_{T} \quad$ :thrust coefficient

$\eta_{t} \quad$ :thrust efficiency

$\eta_{u} \quad$ :propellant utilization

$\theta_{b} \quad$ :beam divergence angle

\section{Introduction}

An ion thruster is one of candidates for primary propulsion of deep space missions because it produces high thrust efficiency with a specific impulse of 3000-8000 $\mathrm{s}^{1)}$. Long lifetime is also required for deep space missions. A microwave discharge ion source would offer a potentially longer lifetime than a conventional electron bombardment-type ion source, since it would be free from contamination and degradation of electron emission capacity ${ }^{2,3)}$. Indeed, four $400 \mathrm{~W}$ thrusters are now being used as primary propulsion for a Japanese space probe "HAYABUSA" exploring an asteroid. It was launched on May 2003. And it succeeded in rendezvousing with the asteroid "Itokawa" in September 2005 and touching down on it in November 2005 after a 2-year flight. Now, HAYABUSA has already started on its return journey and is running to aim to reach the Earth in June 2010 $0^{4-6)}$.

For ion thrusters, the low ionization potential of the propellant is the better propellant, therefore, mercury, xenon, etc., have been used as the propellant. However, the activated gas, such as mercury, is not compatible with spacecraft due to its condensation and chemical reaction. Therefore, xenon has been the preferred propellant for ion thrusters because it is an inert gas, and because of its high thrust efficiency due to its low ionization potential and large molecular mass.

For deep space missions, the power supply that doesn't depend on the distance from the Sun is needed. Consequently, Nuclear Electric Propulsion System (NEPS), mounting nuclear reactor in space explorer and running electric propulsion system, would be adopted. ${ }^{7)}$ The NEPS has some advantages on deep space mission because of its high thrust and high specific impulse, since it produce large amount of power that doesn't depend on the distance from the Sun. So, the priority of thrust efficiency becomes lower than that of specific impulse and cost. Therefore, argon would be better than xenon as the propellant due to low cost and enough supply, although the higher ionization potential of the argon results in an efficiency deficit. In addition, argon has some advantage in lifetime, since its sputtering yield is less than that of xenon when the specific impulses are the same.

The aim of this study is measuring the thrust performance in the microwave discharge ion thruster 
using argon as the propellant. In this paper, we use two ion thrusters, one is $10 \mathrm{~cm}$ class and the other is $2 \mathrm{~cm}$ class.

\section{Experimental setup}

The experimental apparatus is composed of microwave transmission system, evacuated system and ion thruster. The frequency of microwave generator used is $2.45 \mathrm{GHz}$. A $0.6 \mathrm{~m}$ diameter by $1 \mathrm{~m}$ long vacuum chamber was used in the experiments. The pumping system comprised a cryo-pump and a turbo molecular pump. The background pressure was maintained below $5 \times 10^{-3}$ Pa for most of the operating conditions. Argon gas (99.99\%), high-pure krypton gas(99.999\% pure) and high-purity (99.999\% pure) xenon gas were used as the propellant. To supply and control the propellant mass flow, mass flow controller (BROOKS 5850S) is used. The extracted ion beam was estimated as the current through the screen power supply minus the current through the accelerator power supply. The validity of this method was shown in our previous study. ${ }^{8)}$ A neutralizer was not used in this study, as there is little difference between the extracted ion beam current without a neutralizer and that with a filament neutralizer $(\phi=0.2 \mathrm{~mm} \times 100 \mathrm{~mm}, 2 \%$ thoriated tungsten). There are several candidates for the neutralizer of this thruster, including a field emission cathode, ${ }^{9,10)}$ a filament cathode, a internal conduction cathode, ${ }^{11)}$ and a microwave discharge cathode. ${ }^{12)} \mathrm{A}$ miniature microwave discharge neutralizer is under development, although it has thus far shown poor performance. $^{12)}$

Figure 1 shows a $10 \mathrm{~cm}$ class microwave discharge ion thruster developed at Kyushu University ${ }^{13,14)}$. Emitted microwaves from the emitting antenna can be distributed to any antennas in the radial-waveguide. A receiving antenna can be set up in anywhere, and the distribution ratio of microwave power can be controlled by changing the antenna position, the length, and the diameter of the receiving antenna. The receiving antennas emit the microwaves in the discharge chamber and the emitted microwaves heat electrons. The thruster itself can be insulated electrically from a microwave generator, since coaxial cable is insulated from radial-waveguide. So, the thruster can reduce the number of parts and can be miniaturized. There would be little dissipation of the microwave power in the radial waveguide, since there does not exist standing waves by our numerical calculation. ${ }^{15)}$ The diameter and the length of discharge chamber are $105 \mathrm{~mm}$ and $25 \mathrm{~mm}$, respectively. The length of discharge chamber is $25 \mathrm{~mm}$. Magnetic circuit is formed by samarium-cobalt ( $\mathrm{Sm}-\mathrm{Co}$ ) permanent magnets and yokes which are made of soft iron. It has two magnetic tracks formed by two lines of the Sm-Co magnet on the base yoke and one line on the side yoke due to expanded distance of magnetic tube, as shown in Fig.2.

The antennas are made of Mo (1.5 $\mathrm{mm}$ in diameter). They are set on an electron cyclotron resonance (ECR) layer in a magnetic tube between the magnets, as shown in Fig. 2. A grid system for extracting ions from the discharge chamber is composed of a screen grid, an acceleration grid and a deceleration grid. The grid configurations are the same as that of Laboratory Model in MUSES- $\mathrm{C}^{3)}$. The geometric parameters are shown in Table 1. The gap between the grids is $0.5 \mathrm{~mm}$ and the ion beam diameter is $105 \mathrm{~mm}$.

The cross section of a $2 \mathrm{~cm}$ class miniature microwave discharge ion thruster is shown in Fig. 3. The inner diameter is $21 \mathrm{~mm}$ and the size of the thruster is 50 $\mathrm{mm} \times 50 \mathrm{~mm} \times 30 \mathrm{~mm}$. The ion source consists of a magnetic circuit, which has several Samarium Cobalt (Sm-Co) permanent magnets and iron yokes. The magnetic flux density in the discharge chamber can be changed by changing the numbers of the permanent magnets. Microwave power at $2.45 \mathrm{GHz}$ was fed through a coaxial line and into an antenna. A star antenna is used, since it showed good performance in our previous study. ${ }^{16)}$ The antenna is inscribed in a $9 \mathrm{~mm}$ diameter circle and is made of molybdenum. The thickness of it is $1 \mathrm{~mm}$.

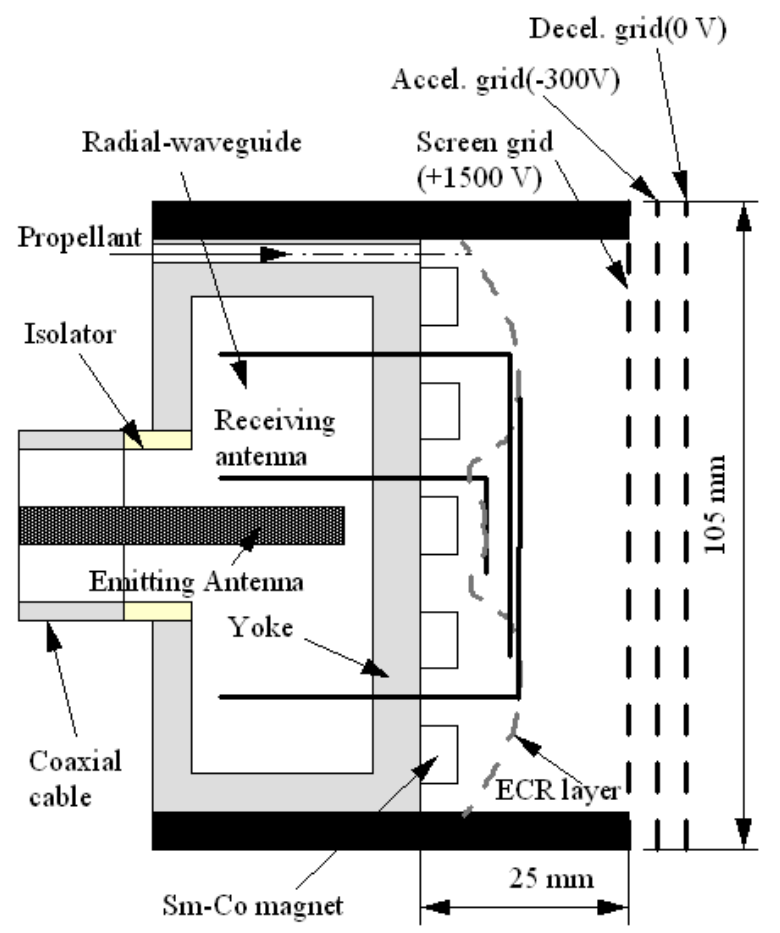

Fig. $1.10 \mathrm{~cm}$ class microwave ion thruster developed at Kyushu Univ.

Table 1 Grid parameters.

\begin{tabular}{cccc}
\hline \hline Parameter & Screen & Accel & Decel \\
\hline Open area ratio, \% & 67 & 24 & 67 \\
Hole diameter, mm & 3.0 & 1.8 & 3.0 \\
Potential, V & 1,500 & -300 & 0 \\
Thickness, mm & 0.5 & 0.8 & 0.5 \\
Hole pitch, mm & & 3.50 & \\
Grid gap, mm & & 0.5 & \\
Number of holes & & 857 & \\
\hline \hline
\end{tabular}




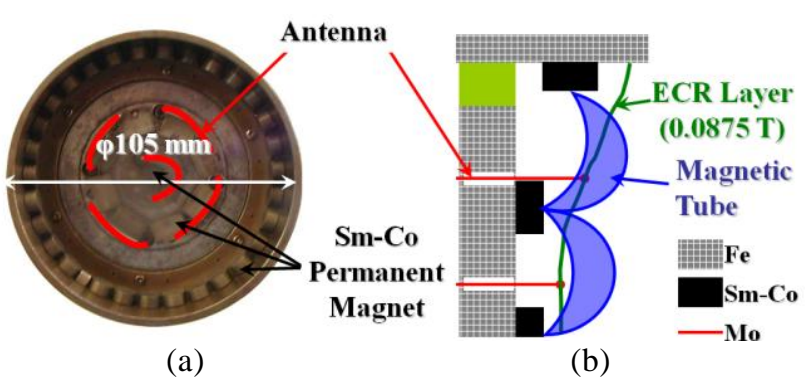

Fig. 2.Magnetic field profile of the $10 \mathrm{~cm}$ class ion thruster developed at Kyushu University, (a) Front view, (b) Cross section

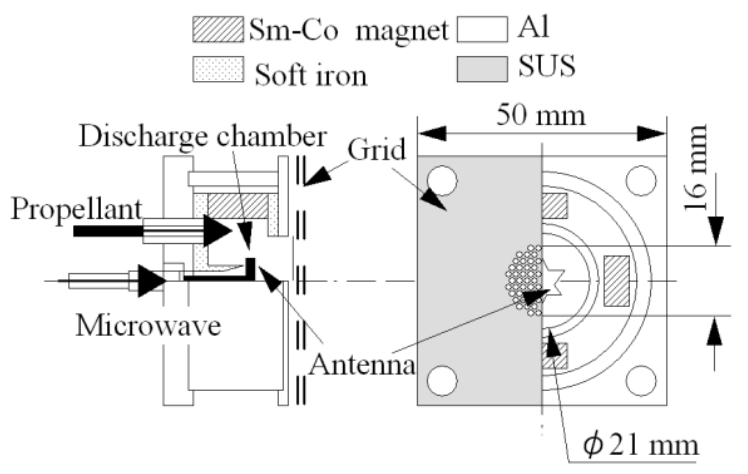

Fig.3. Cross-section of miniature ion thruster developed at Kyushu University

Table 2. Grid Parameters

\begin{tabular}{ccc}
\hline \hline Parameter & Screen & Acceleration \\
\hline Open area ratio, \% & 51 & 16 \\
Hole diameter, mm & 1.20 & 0.70 \\
Potential, V & 1000 & -200 \\
Thickness, mm & & 0.30 \\
Hole pitch, mm & 1.20 & \\
Grid gap, mm & 0.20 & \\
Number of holes & 91 & \\
\hline \hline
\end{tabular}

The tip of the antenna is inserted into the magnetic tube formed by the magnetic circuit. A DC block with a loss of $0.43 \mathrm{~dB}$ at $2.45 \mathrm{GHz}$ was inserted to protect the microwave amplifier. Flat circle grids were used to extract the ion beam. The geometric parameters are shown in Table 2. This geometry was designed using a numerical analysis code developed by Arakawa et al. ${ }^{17)}$ The grid is made of molybdenum and ceramic cylinders are used as the isolators between the two grids. The gap between the grids is $0.2 \mathrm{~mm}$ and the ion beam diameter is $16 \mathrm{~mm}$. The screen grid and ion source were biased to $+1,000 \mathrm{~V}$ with respect to ground and the acceleration grid was set to $-200 \mathrm{~V}$.

\section{Results and Discussion}

In order to evaluate the performance of the ion engine, ion beam production cost, $\varepsilon_{c}$, propellant utilization, $\eta_{u}$, thrust, $F$, specific impulse, $I_{s p}$, and thrust efficiency, $\eta_{t}$ are defined as,

$$
\begin{aligned}
\varepsilon_{C} & =\left(P_{i}-P_{r}\right) / I_{B} \\
\eta_{u} & =\frac{I_{b}}{\left(e / m_{i}\right) \cdot \dot{m}_{i}} \\
F & =\gamma_{T} I_{b} \sqrt{\left(2 m_{i} V_{b} / e\right)} \\
I_{s p} & =F /\left(\dot{m}_{i} g\right) \\
\eta_{t} & =\frac{\gamma_{T}^{2} \eta_{u}}{1+\varepsilon_{C} / V_{b}}
\end{aligned}
$$

Considering the exhaust-beam divergence and the effect of doubly charged ion, $\gamma_{\mathrm{T}}$ is defined as,

$$
\gamma_{T}=\cos \theta_{b} \times(1+\alpha / \sqrt{2}) /(1+\alpha)
$$

$\alpha$ and $\theta_{b}$ are assumed to be 0.15 and 10 degrees, respectively. ${ }^{18,19)}$ Thus, in this study, $\gamma_{T}$ is estimated as $\gamma_{T} \approx 0.98 \times 0.96=0.94$

\section{1. $10 \mathrm{~cm}$ class ion thruster}

Figure 4 shows the relation between incident microwave power and ion beam current. The ion beam currents with argon propellant are small compared to those with xenon below $24 \mathrm{~W}$. On the other hand, ion beam currents with argon are larger than those with xenon propellant at $P_{\mathrm{i}}>24 \mathrm{~W} ; I_{\mathrm{b}}$ with xenon propellant and argon one are $69 \mathrm{~mA}$, and $77 \mathrm{~mA}$, respectively for $P_{i}=$ $32 \mathrm{~W}$. This would be due to the following reason. That is, in the case of argon, electrons can get enough energy whole over the discharge chamber, since less neutral density and smaller ionization cross section than xenon will not prevent electron energy gain processes. Therefore plasma emission from the discharge chamber is uniform as shown in Fig.5. Though the ionization potential of argon is high, it can be compensated by high incident microwave power. Therefore, ion beam is increased with increase in the incident power. These results suggest that there are optimum magnetic tube lengths, i.e., the distances between magnet lines for variety of propellants and its densities. Overall, the thruster performance for argon propellant with $P_{i}=37 \mathrm{~W}$; propellant utilization efficiency, ion beam production cost, estimated thrust, estimated specific impulse and estimated thrust efficiency are $0.50,440 \mathrm{~W} / \mathrm{A}, 2.8 \mathrm{mN}, 4200 \mathrm{sec}$, and 0.34 , respectively.

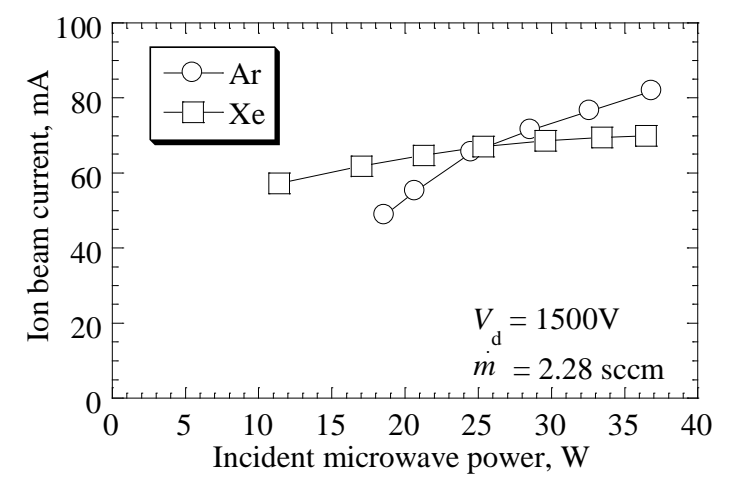

Fig 4. Relation between incident microwave power and ion beam current 


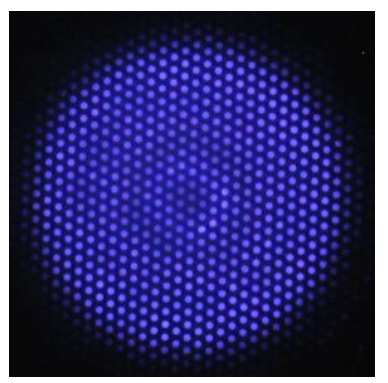

(a)

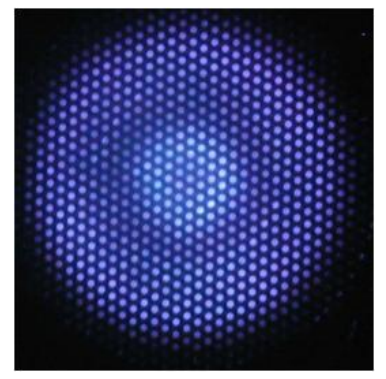

(b)
Fig 5. Pictures of plasma emission. (a) argon, and (b) xenon, $\dot{m}=2.05 \mathrm{sccm}, P_{i}=32 \mathrm{~W}$, and $V_{b}=1,500 \mathrm{~V}$

\subsection{Miniature ion thruster}

Figure 6 shows the relation between incident microwave power and ion beam current for the three gases at $\dot{m}_{i}=0.03 \mathrm{sccm}$. For $P_{\mathrm{i}}=10 \mathrm{~W}$, the ion beam currents of xenon, krypton and argon are $13.9 \mathrm{~mA}, 11.3 \mathrm{~mA}$, and 6.5 $\mathrm{mA}$, respectively. That is, the ion beam currents with xenon are the largest among the three, and those with argon is the smallest of all, and these are reasonable due to the difference in the cross section of the ionization and in neutral number density. However, the ion beam currents of argon are almost half of those of krypton. This poor performance of argon would be due to the lower pressure inside the discharge chamber. The conductance with argon through the grid is about twice larger than that of krypton, since the mass of argon is twice lighter than that of krypton.

Therefore, the dependence of mass flow rate (i.e. pressure inside the discharge chamber) on thrust performance was investigated. Figure 7 shows the relation between incident microwave power and ion beam current for four mass flow rates. As expected, the ion beam currents increase with increase in mass flow rate. The ion beam currents, however, becomes saturated beyond 0.6 sccm at $P_{\mathrm{i}}>12 \mathrm{~W}$. Too much mass flow rate doesn't improve the thrust performance. In this configuration, the optimum mass flow rate is $0.4 \mathrm{sccm}$. For krypton mass flow rate of $0.4 \mathrm{sccm}$ and $P_{\mathrm{i}}$ of $16 \mathrm{~W}$ ion beam current is $15.2 \mathrm{~mA}$. On the other hand, ion beam current for 0.4 sccm argon and $P_{\mathrm{i}}$ of $16 \mathrm{~W}$ is $12.8 \mathrm{~mA}$, this is good performance considering the difference of ionization cross section between argon and krypton.

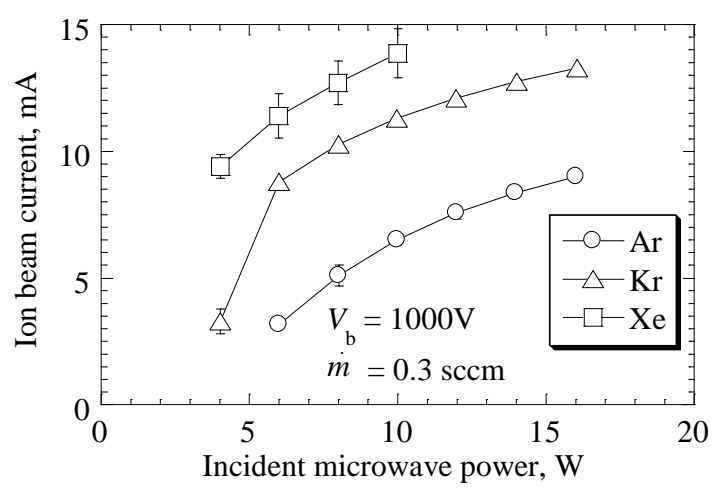

Fig 6. Ion beam current for three gases.

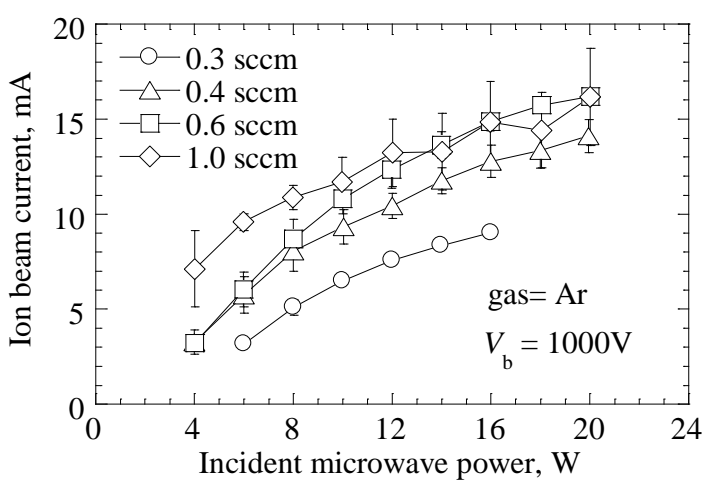

Fig 7. Ion beam current for four mass flow rates.

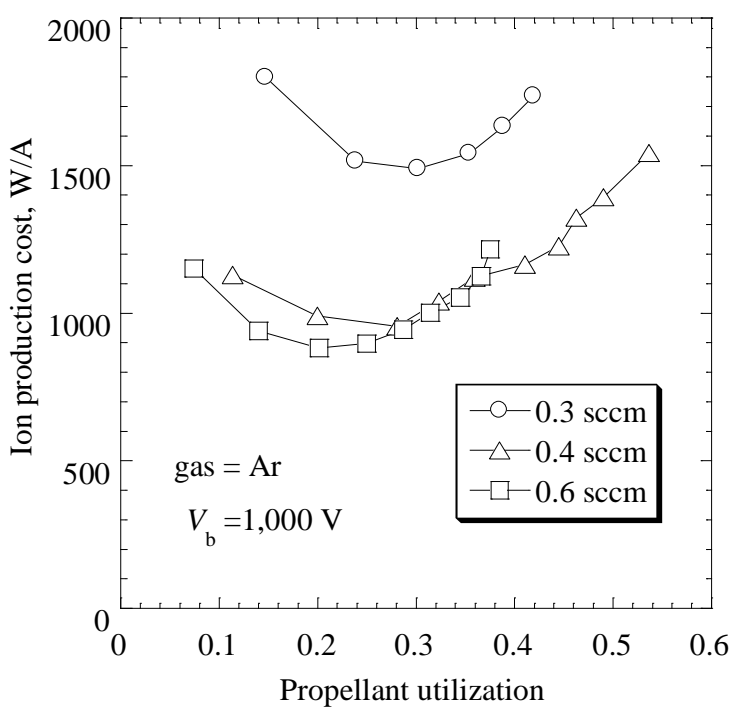

Fig 8. Thrust performance for three mass flow rates. $V_{b}=1,000 \mathrm{~V}$.

The optimum mass flow rate using argon is higher than that using xenon, $0.2 \mathrm{sccm}^{16)}$, this would be due to the smaller ionization cross section and lighter mass than those of xenon.

Figure 8 shows the thrust performance of the argon propellant for three flow rates. The propellant utilization decreases with an increase in mass flow rate for a given level of power, since specific energy decreases with an increase in mass flow rate. Though ion beam production cost decreases with an increase in propellant utilization below 0.3 for all mass flow rates, this would be due to the low microwave-plasma coupling. The thrust performance of the miniature ion thruster with argon as the propellant, that is, $\eta_{\mathrm{u}}, \varepsilon_{\mathrm{c}}, F, I_{\mathrm{sp}}$ and $\eta_{\mathrm{t}}$ are $0.44,1,200 \mathrm{~W} / \mathrm{A}, 0.34 \mathrm{mN}$, $2.9 \times 10^{3} \mathrm{sec}$ and 0.18 , respectively at $\dot{m}=0.4 \mathrm{sccm}$ and $P_{\mathrm{i}}$ $=16 \mathrm{~W}$.

The magnetic field configuration, magnitude and profile of the magnetic field, should be optimized in order to improve the thrust performance of this ion thruster using argon as the propellant.

Ion beam currents are measured using an ion source with longer magnetic tube than that shown in Fig.3. The magnetic field profile of this ion thruster is shown in 
Fig.9. The magnetic tube is about $16 \mathrm{~mm}$, which is about 3 times longer than that of the previous miniature ion thruster. Figure 10 shows the ion beam current of improved ion thruster for xenon gas and argon gas at $\dot{m}=0.4 \mathrm{sccm}$ and $V_{\mathrm{b}}=1000 \mathrm{~V}$. When propellant is argon, a hysteresis was observed. The ion beam current suddenly jumps up to $13 \mathrm{~mA}$ from $5 \mathrm{~mA}$ at $P_{\mathrm{i}}=$ around 11 W with increase in $P_{\mathrm{i}}$, however, the ion beam current suddenly drops at $P_{\mathrm{i}}=9 \mathrm{~W}$. Microwave- plasma coupling is changed with this change; the reflected microwave power at low coupling is about $3 \mathrm{~W}$ at $P_{\mathrm{i}}=10 \mathrm{~W}$, while that with good coupling(ion beam current is large at this condition) becomes almost $0 \mathrm{~W}$. This critical incident power decrease with increase in mass flow rate; it is around $12 \mathrm{~W}$ at argon mass flow rate is $0.3 \mathrm{sccm}$ and $7 \mathrm{~W}$ at argon mass flow rate is $0.6 \mathrm{sccm}$. These results shows that if plasma density is enough high, this hop will be appeared.

As the results in 3.1, the ion beam current using argon is larger than that using xenon beyond critical incident microwave power, and the ion beam current achieved 20.8 $\mathrm{mA}$ at at $P_{\mathrm{i}}=16 \mathrm{~W}$, while that using xenon is 16.6 at the same condition. The reason of this reverse tendency is the same as that in 3.1, that is, too much mass flow rate suppress the electron temperature in the discharge chamber, because of the increase in collision frequency.

Overall, the thrust performance of the miniature ion thruster with argon as the propellant, that is, $\eta_{\mathrm{u}}, \varepsilon_{\mathrm{c}}, F, I_{\mathrm{sp}}$ and $\eta_{\mathrm{t}}$ are $0.73,750 \mathrm{~W} / \mathrm{A}, 0.57 \mathrm{mN}, 4.9 \times 10^{3} \mathrm{sec}$ and 0.37 , respectively at $\dot{m}=0.4 \mathrm{sccm}, V_{\mathrm{b}}=1,000 \mathrm{~V}$ and $P_{\mathrm{i}}=16 \mathrm{~W}$. This performance shows that the argon competes against xenon as the propellant for miniature ion thruster, though the best thrust performance with the configuration optimized for xenon ${ }^{20,21)}$ is still superior to above performance.

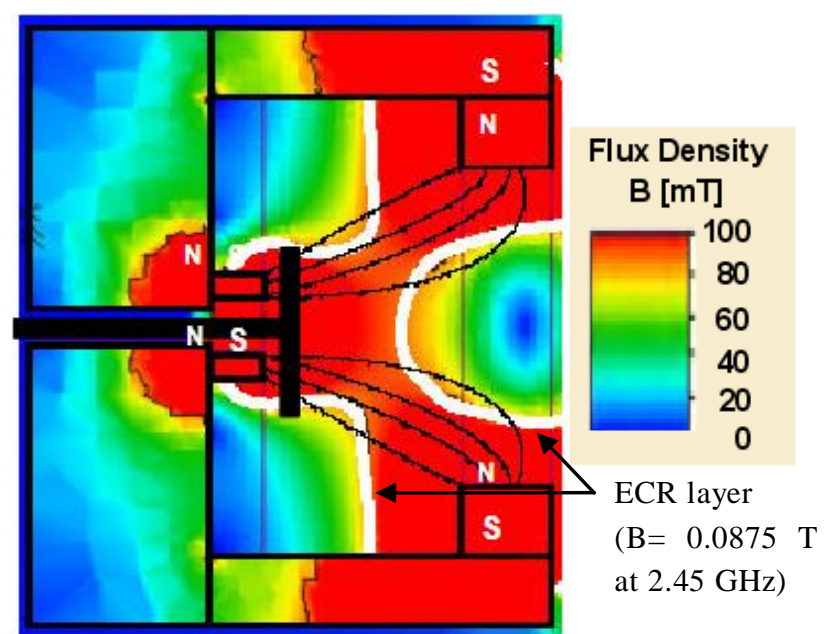

Fig 9. Magnetic field profile of ion thruster with long magnetic tube developed at Kyushu University.

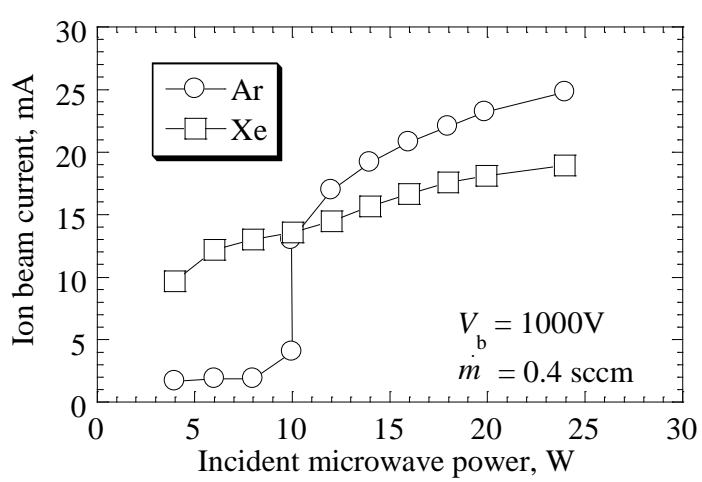

Fig 10. Ion beam current for two gases, $\dot{m}=0.4 \mathrm{sccm}$ and $V_{b}$ $=1,000 \mathrm{~V}$.

\section{Summary}

The thrust performance of ion thrusters using argon as the propellant was measured for the possibility as the alternative propellant in ion thrusters. Two class ion thrusters, $10 \mathrm{~cm}$ class ion thruster and $2 \mathrm{~cm}$ class were used.

First, the ion beam current of $10 \mathrm{~cm}$ class was measured. The ion beam currents with argon are larger than those with xenon propellant at $P_{\mathrm{i}}>24 \mathrm{~W}$. This would be due to the difference of electrons energy. Since the frequency that electrons cross through the ECR layer is different between the two gases, because of the different mean free path. This means, the optimum magnetic tube length using argon is longer than that of xenon. The thruster performance for argon propellant with $P_{i}=37 \mathrm{~W}$; propellant utilization efficiency, ion beam production cost, estimated thrust, estimated specific impulse and estimated thrust efficiency are $0.50,440 \mathrm{~W} / \mathrm{A}, 2.8 \mathrm{mN}, 4,200 \mathrm{sec}$, and 0.34 , respectively.

Next, the ion beam currents of $2 \mathrm{~cm}$ class ion thruster were measured. The optimum mass flow rate is $0.4 \mathrm{sccm}$, which is larger than that using xenon $(0.2 \mathrm{sccm})$, this would be due to the smaller ionization cross section and lighter mass than those of xenon. The thrust performance of the miniature ion thruster with argon as the propellant, that is, $\eta_{\mathrm{u}}, \varepsilon_{\mathrm{c}}, F, I_{\mathrm{sp}}$ and $\eta_{\mathrm{t}}$ are $0.44,1,200 \mathrm{~W} / \mathrm{A}, 0.34 \mathrm{mN}$, $2.9 \times 10^{3} \mathrm{sec}$ and 0.18 , respectively at $\dot{m}=0.4 \mathrm{sccm}$ and $P_{\mathrm{i}}$ $=16 \mathrm{~W}$. This performance is thus far inferior to those using xenon.

For improvement of the thrust performance, the antenna shape, magnetic field strength, magnetic field shape, among other factors should be optimized.

Last, ion beam currents of the miniature ion thruster with long magnetic tube are measured in order to improve the thrust performance of miniature ion thruster using argon. The ion beam current achieved $20.8 \mathrm{~mA}$, which is 1.6 times larger than that of normal type. This is almost the same performance as the best performance using xenon in miniature microwave discharge ion thruster developed at Kyushu University, though this ion source is inadequate for small power range(for example, $P_{\mathrm{i}}<12 \mathrm{~W}$ at $\dot{m}=0.04 \mathrm{sccm}$.) 
Overall, the thrust performance of the miniature ion thruster with argon as the propellant, that is, $\eta_{\mathrm{u}}, \varepsilon_{\mathrm{c}}, F, I_{\mathrm{sp}}$ and $\eta_{\mathrm{t}}$ are $0.73,750 \mathrm{~W} / \mathrm{A}, 0.57 \mathrm{mN}, 4.9 \times 10^{3} \mathrm{sec}$ and 0.37 , respectively at $\dot{m}=0.4 \mathrm{sccm}, V_{\mathrm{b}}=1,000 \mathrm{~V}$ and $P_{\mathrm{i}}=16 \mathrm{~W}$. these results shows that the possibility of argon as the alternative propellant of xenon. There is still some room to improve the performance of miniature ion thruster, such as grid parameters, antenna shape, magnetic field strength, magnetic field shape, among other factors.

\section{Acknowledgments}

The present work was supported by a Grant-in-Aid for Scientific Research(C)(2), No.16560691, (C) No.9560792, and a Grant-in-Aid for Young Scientists (B), No. 17760638, sponsored by the Ministry of Education, Culture, Sports, Science and Technology, Japan.

\section{References}

1) Wilbur, P. J., Rawlin, V. K. and Beattie, J. R.: Ion Thruster Development Trends and Status in the United States, $J$. Propulsion and Power, 14 (1998), pp.708-715.

2) Kuninaka, H., and Satoru, S.: Development and Demonstration of Cathodeless Electron Cyclotron Resonance Ion Thruster, J. of Propulsion and Power, 14 (1998), pp. 1022-1026.

3) Funaki, I., Kuninaka, H., Toki, K., Shimizu Y., Nishiyama, K., and Horiuchi Y.: Verification Tests of Carbon-Carbon Composite Grids for Microwave Discharge Ion Thruster, J. of Propulsion and Power, 18 (2002), pp. 169-175.

4) Kawaguchi, J., Uesugi, K, and Fujiwara, A.: The MUSES-C mission for the sample and return -its technology development status and readiness-, Acta Astronautica, 52 (2003), pp.117-123.

5) Fujiwara, A., Kawaguchi, J., Yeomans, D. K., Abe, M., Mukai, T., Okada, T. Saito, J., Yano, H., Yoshikawa, M., Scheeres, D. J., Barnouin-Jha, O., Cheng, A. F., Demura, H., Gaskell, R. W., Hirata, N., Ikeda, H., Kominato, T., Miyamoto, H., Nakamura, A. M., Nakamura, R., Sasaki, S. and Uesugi, K.: The rubble-pile asteroid Itokawa as observed by Hayabusa", Science, 312 (2006), pp.1330-1334.

6) Funaki, I., Kuninaka, H., and Toki, K.: Plasma Characterization of a 10-cm Diameter Microwave Discharge Ion Thruster, J. of Propulsion and Power, 20 (2004), pp. 718-726.

7) El-Genk M, S, editor,: A Critical Review of Space Nuclear Power and Power and Propulsion, American Institute of Physics Press (1994), pp.1984-1993.

8) Takao, Y., Miyamoto, T., Kataharada, H., Nakashima, H., Masui, H., Kai, T., Ijiri, H., Mori, and Y., Yamamoto, N.: Development of Small-Scale Ion Thruster Utilizing Microwave Discharge Plasma, Proc. of the 24th International Symposium on Space Technology and Science, ed. by J. Onodera, Japan Society for Aeronautical and Space Sciences and Organizing Committee of the 24th ISTS, Tokyo, Japan, (2004), pp. 161-166.
9) Okawa, Y., Kitamura, S., Kawamoto, S., Iseki, Y., Hashimoto, K., and Noda, E.: An Experimental Study On Carbon Nanotube Cathodes For Electrodynamic Tether Propulsion, 56th International Astronautics Congress Paper, IAC-05-C4.4.07, Oct. 2005.

10) Yamamoto, A., Nakai, H., Kaneko, N., Nakashizu, T., Ohsawa, S., Sugimura, T., and Ikeda, M.: The Research On the Carbon Nano Tube Cathode, Proceedings of the 2003 Particle Accelerator Conference,(2003), pp.3326-3328.

11) Wirz, R., Gale, M., Mueller, J., and Marrese, C.: Miniature Ion Thrusters for Precision Formation Flying, AIAA paper 2004-4115, July 2004.

12) Tanisho, M., Kataharada, H., Yamamoto, N., Nakashima, H.: A Miniaturized Ion Thruster and Neutralizer with Microwave Discharge, 56th International Astronautics Congress Paper, IAC-05-CIAC-05-C4.4.02, 2005.

13) Miyamoto, T., Yamamoto, N., and Hideki, N.: Development of a Microwave Discharge Ion Engine by Using Monopole Antennas, Proc. of the 24th International Symposium on Space Technology and Science, ed. by J. Onodera, Japan Society for Aeronautical and Space Sciences and Organizing Committee of the 24th ISTS, Tokyo, Japan, 2004, pp. 137-142.

14) Miyamoto, T., Mii, K., Nishijima, T., Takao, Y., and Hideki, N., "Development of a New Microwave Discharge Type Ion Engine, Vacuum, ,73 (2004), pp. 391-396.

15) Masui, H., Yamamo, N., Nakashima, H., and Funaki, I.: Analysis of Plasma Behavior in Microwave Discharge Ion Engine, AJCPP Paper, AJCPP-A2051, Jan, 2005.

16) Yamamoto, N., Masui, H., Kataharada, H., Nakashima, H., and Takao, Y.: Antenna Configuration Effects on Thrust Performance of Miniature Microwave Discharge Ion Engine, $J$. of Propulsion and Power Technical Note, 22 (2006), pp.925-928.

17) Nakano, M. , Tachibana, T., and Arakawa, Y.: A Scaling Law of the Life Estimation of the Three-Grid Optics for an Ion Engin, Trans. of the Japan Society for Aeronautical and Space Sciences, 45 (2002), pp.154-161.

18) Satori, S., Kuninaka, H., and Otaki, M.,: Beam Diagnostics of a Microwave Discharge Ion Engine,The Japan Society for Aeronautical and Space Sciences, 46 (1998), pp.406-412 (in Japanese).

19) Takegahara, H., Kasai, Y., Gotoh, Y., Miyazaki, K., Hayakawa, Y., Kitamura, S., Nagano, H., and Nanamura, K.: Beam Characteristics Evaluation of ETS-VI Xenon Ion Thruster, IEPC Paper 93-235, Electric Rocket Propulsion Society, Sept. 1993.

20) Yamamoto, N., Kondo, S., Chikaoka, T., Masui, H., and Nakashima, H.: Effects of magnetic field configuration on thrust performance in a miniature microwave discharge ion thruster, J. Applied Physics, 102 ( 2007), 123304.

21) Kondo, S., Chikaoka, T., Yamamoto, N., Majima, A., Yamada, T., Tomita, K., Nakashima, H., Uchino K.: Internal Plasma Structure Measurement in a Miniature Microwave Discharge Ion Thruster, IEPC Paper 2007-101, Electric Rocket Propulsion Society, Sept. 2007 